\title{
In Vitro Antiplasmodial Activity and Cytotoxicity of Extracts of Selected Medicinal Plants Used by Traditional Healers of Western Cameroon
}

\author{
Denis Zofou, ${ }^{1}$ Mathieu Tene, ${ }^{2}$ Moses N. Ngemenya, ${ }^{1}$ Pierre Tane, ${ }^{2}$ and Vincent P. K. Titanji ${ }^{1}$ \\ ${ }^{1}$ Biotechnology Unit, University of Buea, P.O. Box 63 Buea, South West Region, Cameroon \\ ${ }^{2}$ Laboratory of Natural Products Chemistry, University of Dschang, P.O. Box 67 Dschang, West Region, Cameroon
}

Correspondence should be addressed to Vincent P. K. Titanji, vpk.titanji@yahoo.com

Received 22 September 2010; Revised 18 January 2011; Accepted 24 January 2011

Academic Editor: Polrat Wilairatana

Copyright (c) 2011 Denis Zofou et al. This is an open access article distributed under the Creative Commons Attribution License, which permits unrestricted use, distribution, and reproduction in any medium, provided the original work is properly cited.

\begin{abstract}
Medicinal plants play a key role in malaria control in Africa, especially in remote areas where health facilities are limited. In order to assess their acclaimed potentials, eleven extracts were prepared from seven selected plants commonly used in Western Cameroon, and tested both for their antiplasmodial activity and cytotoxicity. The antiplasmodial activity was assessed using Lactate Dehydrogenase Assay (pLDH) and the cytotoxicity estimated on LLC-MK2 monkey kidney epithelial cells. Seven extracts from five different plants were significantly active, with very weak or no cytotoxicity. The Dacryodes edulis leaves showed the highest activity $\left(\mathrm{IC}_{50}\right.$ of $6.45 \mu \mathrm{g} / \mathrm{mL}$ on $3 \mathrm{D} 7 \mathrm{and} 8.2 \mu \mathrm{g} / \mathrm{mL}$ on DD2) followed by the leaves of Vernonia amygdalina ( $\mathrm{IC}_{50}$ of $8.72 \mathrm{and} 11.27 \mu \mathrm{g} / \mathrm{mL}$ on 3D7 and DD2 resp.) and roots of V. amygdalina ( $\mathrm{IC}_{50}$ of $8.72 \mu \mathrm{g} / \mathrm{mL}$ on 3D7), Coula edulis leaves ( $\mathrm{IC}_{50}$ of $13.80 \mu \mathrm{g} / \mathrm{mL}$ and $5.79 \mu \mathrm{g} / \mathrm{mL}$ on 3D7 and DD2 resp.), Eucalyptus globulus leaves ( $\mathrm{IC}_{50}$ of $16.80 \mu \mathrm{g} / \mathrm{mL}$ and $26.45 \mu \mathrm{g} / \mathrm{mL}$ on 3D7 and DD2) and Cuviera longiflora stem bark ( $\mathrm{IC}_{50}$ of $20.24 \mu \mathrm{g} / \mathrm{mL}$ and $13.91 \mu \mathrm{g} / \mathrm{mL}$ on $3 \mathrm{D} 7 \mathrm{and} \mathrm{DD} 2$ ). These findings justify the use of five of the seven plants in malaria treatment by traditional healers of Western Cameroon.
\end{abstract}

\section{Introduction}

Malaria is the world's most important parasitic disease especially when Plasmodium falciparum is the causative agent. From the recent World Malaria Report, there were an estimated 225 million malaria cases, with 800,000 deaths among the 3 billion people at risk in 2009. About $91 \%$ of total deaths occurred in Africa with pregnant women and children under 5 years being the most affected groups of the populations [1]. Cameroon figures among the 18 countries bearing $90 \%$ of malaria deaths in Africa, with $71 \%$ of its population living in high-transmission areas [2]. In the western region of Cameroon, for example, malaria was shown to be the most important cause of infant mortality causing about $45 \%$ deaths and $54 \%$ hospitalizations for children under five [3]. In the absence of an effective vaccine, the fight against malaria relies mainly on chemotherapy and vector control. The resistance of Plasmodium falciparum to the commonly used antimalarial drugs including the newly introduced Artemisinins has resulted in resurgence in treatment failures $[4,5]$. Hence, new highly efficacious and affordable antimalarial agents are urgently needed. For hundreds of years, plants have constituted the basis of traditional medicine systems and natural products have been a good source for drug development. Some examples are Quinine and Artemisinin that have been used successfully against resistant strains of malaria parasites. In some rural areas of Cameroon, antimalarial traditional medicines are even preferred to pharmaceutical compound drugs, suggesting that the herbal preparations used by traditional healers contain useful active ingredients [6]. The office of Traditional Medicine at the Public Health Ministry promotes and coordinates Traditional Medicine Practice in Cameroon. However many gaps still remain to fully exploit the potential of herbal medicines as a solution to the malaria burden and this demands combined efforts from public sector, research institutions, funding bodies and pharmaceutical groups, traditional healers, and the populations themselves. 
A previous review by Titanji et al. [5] showed that over 200 different plant species have been identified in Cameroon for their use as antimalarial in folk medicine. But only 26 species had undergone full investigation leading to isolation and testing of pure products, up to 137 species remaining untested [7]. Therefore, there is a need to pursue investigations on the plants so far identified in order to foster and standardize their use either as herbal medicines or sources of new drug candidate molecules. The present study thus aims at screening the crude extracts from seven widely used plants, namely, methylene chloride/methanol $(1: 1)$ extracts of Cuviera longiflora, Dacryodes edulis and Eucalyptus globules leaves, Vernonia amygdalina leaves and roots, the hexane and methylene chloride extracts of Kotschya speciosa aerial part and the methylene chloride extracts of the whole plant, the methanol extract of Coula edulis stem bark, the methylene chloride/methanol (1:1), and methylene chloride extracts of Vismia guinensis stem bark, for their postulated antiplasmodial activity.

\section{Materials and Methods}

2.1. Collection of Plants Materials. All the plant parts were collected in Batcham (Bamboutos division, Western Region Cameroon) in April 2008. The sample identification was confirmed at the Cameroon National Herbarium by matching them with existing Voucher specimens deposited at the same institution in Yaounde.

2.2. Preparation of Crude Extracts. The air dried and powdered plant material (3.5 Kg of each) was macerated for three days at room temperature separately and concurrently in $10 \mathrm{~L}$ of each of the following solvents: a methylene chloride/methanol $(1: 1)$ mixture, methylene chloride, hexane and methanol. The mixture was filtered with Whatman paper, then concentrated to dryness to viscous residues using a Rotavapor system (BÜCHI Labortechnik AG, Switzerland) [5]. The crude extracts prepared were stored at $4^{\circ} \mathrm{C}$ for further use.

2.3. Parasite Strains. The 3D7 (MRA-102) strain was obtained from MR4 (Manassas, VA, USA) and maintained in continuous culture with back up stored in liquid nitrogen.

The DD2 strain was kindly donated to our research team by Prof. Alex Rowe from C.I.I.E of Edinburgh University, UK.

2.4. Plasmodium Falciparum Culture and Maintenance. P. falciparum were grown and maintained in culture using the method of Trager and Jensen with some modification [8]. All the chemicals except Albumax II (Gibco; Invitrogen, USA) were ordered from Sigma-Aldrich Inc (Germany). Cultures consisted of a $4 \%$ hematocrit suspension of $\mathrm{O}+$ human erythrocytes in RPMI 1640 medium supplemented with Gentamicin solution at $0.01 \mathrm{mg} / \mathrm{mL}, 25 \mathrm{mM}$ HEPES buffer, $25 \mathrm{mM} \mathrm{NaHCO}_{3}$, and $1 \%$ Albumax II. Cultures were fed with a gas mixture containing $5 \% \mathrm{CO}_{2}$ and incubated at $37^{\circ} \mathrm{C}$. The estimation of the parasitaemia as well as parasite visualisation before incubation was done using both
Fluorescence (Acridine Orange) and normal light (Giemsa stain) microscopes.

2.5. Determination of In Vitro Antiplasmodial Activity. Drug sensitivity assay was carried out in 96-well microtitration plates as described by Desjardins et al. [9] with some modifications [10]. The crude extracts were dissolved in dimethyl sulfoxide $(200 \mu \mathrm{L})$ and prediluted with culture medium to make a final concentration of $1000 \mu \mathrm{g} / \mathrm{mL}$. All stock solutions were sterilized by passing them through a $0.2 \mu \mathrm{m}$ syringe filter and stored at $-20^{\circ} \mathrm{C}$ until required. Similarly chloroquine stock $(2 \mu \mathrm{g} / \mathrm{mL})$ used as positive control, was prepared from liquid Chloroquine phosphate (Greenfield Pharmaceutical LTD, Jiang Su, China).

Dose-response assay was carried out to obtain the 50\% inhibitory concentration $\left(\mathrm{IC}_{50}\right)$ of the individual drugs. Ring stage infected erythrocytes $(100 \mu \mathrm{L}$ per well with $2 \%$ hematocrit and $1 \%$ parasitaemia) were incubated in triplicate with twofold serial dilution of each drug for 48 hours. Each experiment was performed in duplicate separate experiment. Parasitaemia was measured using the parasite lactate dehydrogenase (pLDH) assay [8].

2.6. Lactate Dehydrogenase ( $p L D H)$ Assay. While incubation of parasites with products was going on, the two reagents for detecting and measuring the LDH enzyme were prepared [8]. The first of these is the Malstat reagent, which was made by dissolving $400 \mu \mathrm{L}$ of Triton X-100 in $80 \mathrm{~mL}$ of deionised water, adding L-lactate $(4.00 \mathrm{~g})$, Tris buffer $(1.32 \mathrm{~g})$, and $0.022 \mathrm{~g}$ of 3 -acetyl pyridine adenine dinucleotide (APAD), adjusting the $\mathrm{pH}$ to 9 with hydrochloric acid, and bringing the volume up to $200 \mathrm{~mL}$ with deionised water. The second reagent is NBT/PES solution, and it was prepared by dissolving nitro blue tetrazolium salt $(0.160 \mathrm{~g})$ and phenazine ethosulfate $(0.008 \mathrm{~g})$ in $100 \mathrm{~mL}$ of deionized water. The solution was stored in a foil-covered container and kept in the refrigerator until required. All reagents for preparing the Malstat reagent and NBT/PES solution were purchased from Sigma-Aldrich Inc. When incubation was complete, plates were harvested and subjected to three 20-minute freezethaw cycles to release the cell content and resuspend the culture. Thereafter, $100 \mu \mathrm{L}$ of Malstat reagent and $25 \mu \mathrm{L}$ of NBT/PES solution were added to each well of a new flatbottomed 96-well microtiter plate in triplicate. Thereafter, the culture in each well was mixed and $20 \mu \mathrm{L}$ of the culture taken from each well and added to the corresponding well of the Malstat plate, $25 \mu \mathrm{L}$ of NTB/PES were then added to each well, thereby initiating the lactate dehydrogenase reaction. Colour development of the LDH plate was monitored colorimetrically at $650 \mathrm{~nm}$ with the aid of a plate reader (Emax-Molecular Devices Corporation, California, USA) after an hour of incubation in the dark.

2.7. Analysis of Test Results from the LDH Assay. The LDH assay generates optical density (OD) values at various concentrations of the drug as raw data. OD values from control wells represent the maximum amount of LDH that is produced by parasites and OD values from blank 
wells represent background LDH activity. A 100\% growth value, which corresponds to maximum LDH activity, was obtained by subtracting the mean OD value of blank wells from that of control wells. Likewise, the growth value at each concentration of the drug was obtained by adjusting OD values from drug-treated wells for background LDH activity (parasite-free red blood cells). These values were then expressed as a percentage of the $100 \%$ growth value and plotted against corresponding concentrations of the drug using GraphPad Software (San Diego California USA, http://www.graphpad.com/) to generate log dose-response curves from which $\mathrm{IC}_{50}$ values were obtained. Each extract were tested in triplicate. $\mathrm{IC}_{50}$ values were $\log$ transformed and expressed as geometric mean $\mathrm{IC}_{50}$ and $95 \%$ confidence intervals for the geometric mean calculated for the replicates. The OD values obtained were also used to verify the different $\mathrm{IC}_{50 \text { s }}$ and determine $\mathrm{IC}_{95}$ values using the software HN-NonLin V1.1 (http://www.malaria.farch.net/). The different $\mathrm{IC}_{50 \text { s }}$ values obtained were then grouped and their means calculated and compared among themselves using Independent-Samples $t$-test.

2.8. Cytotoxicity Study of Extracts. The cytotoxicity of the extracts and pure compounds was estimated against LLCMK2 (ATCC, USA) monkey kidney epithelial cells according to the procedure previously described [11] with some modifications. Cells were cultured in the same conditions as $P$. falciparum. For the determination of the toxicity of the extracts, cells were distributed in 96-well plates at 20,000 cells per well in $100 \mu \mathrm{L}$ culture medium. Cells were allowed to attach for 24 hours. The medium was removed completely the following day, and $100 \mu \mathrm{L}$ of fresh medium added to all the wells. Then, $100 \mu \mathrm{L}$ of crude extract $(1000 \mu \mathrm{g} / \mathrm{mL})$ were added in triplicate in row $\mathrm{H}$ and twofold serial dilution made upward ending at row $\mathrm{B}$, and $100 \mu \mathrm{L}$ of medium added to all the wells to have concentration range of 250-3.90, cells at raw A serving as control without drug. The plates were incubated for 72 hours at $37^{\circ} \mathrm{C}$ in $5 \% \mathrm{CO}_{2}$ air. Cells concentration and viability in the presence of extract or pure compounds were compared with that of control cultures without extracts. The definition of the cytotoxicity used [11] was $\mathrm{CC}_{50}<1.0 \mu \mathrm{g} / \mathrm{ml}$ (high cytotoxicity), $\mathrm{CC}_{50} 1.0$ $10.0 \mu \mathrm{g} / \mathrm{mL}$ (moderate), $\mathrm{CC}_{50} 10.0-30.0 \mu \mathrm{g} / \mathrm{mL}$ (mild), and $\mathrm{CC}_{50}>30 \mu \mathrm{g} / \mathrm{mL}$ (nontoxic). The selectivity index defined as $\mathrm{SI}=\mathrm{CC}_{50} / \mathrm{IC}_{50}$ was also calculated.

\section{Results}

Table 1 summarizes some characteristics of the plant extracts tested in the present study. It can be seen that E. globulus leaves had the highest extraction yield, followed by $V$. amygdalina leaves, whereas $K$. speciosa in hexane recorded the lowest yield.

Table 2 presents the results of antiplasmodial activity and cytotoxicity of the ten extracts tested together with the activity of Chloroquine phosphate. The values of $\mathrm{IC}_{50}$ range from 8.72 to $64.30 \mu \mathrm{g} / \mathrm{mL}$. Seven of the eleven extracts exhibited significant antiplasmodial activity $\left(\mathrm{IC}_{50}<50 \mu \mathrm{g} / \mathrm{mL}\right)$ on both 3D7 and DD2 strains of malaria parasite. These active extracts were prepared from five different plant species: D. edulis, C. longiflora, E. globulus, K. speciosa, and V. amygdalina and C. edulis. The most active extracts were from $D$. edulis followed by $V$. amygdalina with $\mathrm{IC}_{50}$ values below $10 \mu \mathrm{g} / \mathrm{mL}$ on $3 \mathrm{D} 7$ and the lowest $\mathrm{IC}_{50}$ values on the Chloroquine-resistant strain. No sign of cytotoxicity was observed with extracts from $D$. edulis, $V$. guinensis, $V$. amygdalina, and methylene chloride extracts of K. speciosa, whereas extracts from C. edulis, E. globulus, and C. longiflora showed a very low cytotoxicity on LLC/MK2 epithelial cells.

\section{Discussion}

Eleven crude extracts prepared from seven different plant species from Western Cameroon were screened in vitro for their antiplasmodial activity and cytotoxicity.

E. globulus recorded the highest extraction yield (2.02\%), followed by $V$. amygdalina root $(1.85 \%)$, whereas aerial part of Kotschya speciosa (KSH) had the lowest yield. In general, extraction yields were the highest with Methylene Chloride/Methanol (1:1) mixture. This may be because the solvent system extracts both polar and nonpolar constituents, unlike the ones used in extracting the other plants which were either polar or nonpolar solvents.

The antiplasmodial activity of Vernonia amygdalina and Eucalyptus globulus was previously reported [5]. $\mathrm{IC}_{50}$ values range from 6.45 to $65.29 \mu \mathrm{g} / \mathrm{mL}$, with three extracts (DEL, VAL and VAR) exhibiting high activity $\left(1<\mathrm{IC}_{50} \leq 10 \mu \mathrm{g} / \mathrm{mL}\right)$, four with moderate activity on both chloroquine sensible and multiresistant strains of $P$. falciparum $\left(10<\mathrm{IC}_{50} \leq\right.$ $25 \mu \mathrm{g} / \mathrm{mL})$, and one (VGE) with weak activity $\left(25<\mathrm{IC}_{50} \leq\right.$ $50 \mu \mathrm{g} / \mathrm{mL}$ ), whereas three of them (KS, KSR and VGS) showed very weak antiplasmodial activity $\left(50<\mathrm{IC}_{50} \leq\right.$ $100 \mu \mathrm{g} / \mathrm{mL}$ ).

D. edulis exhibited the highest activity, followed by $V$. amygdalina, Coula edulis, and Eucalyptus globulus. D. edulis has a long history of use in folk medicine. It is a multipurpose plant in African folk medicine, as its various parts are used to treat several diseases. It is used in traditional medicine as a remedy for parasitic skin diseases, jigger, mouthwash, tonsillitis, sickle cell, and malaria $[12,13]$. Phytochemical analysis of the leaves revealed the presence of phenolic compounds [14], and several compounds from this class have previously been shown as having antiplasmodial activity [15]. Their presence may, therefore, explain the antiplasmodial activity observed. In Western Cameroon, the leaves of $D$. edulis are boiled with those of Cymbopogon citratus and Mangifera indica in water to form a concoction against malaria, but information concerning in vitro antiplasmodial of the leaves extracts has not been reported earlier. Our findings justifying the use of $D$. edulis as antimalarial could, therefore, be used as background knowledge for further studies of the plant as potential source for antimalarial leads.

The $V$. amygdalina leaves are commonly used to treat malaria and other ailments [4]. Phytochemical screening of $V$. amygdalina revealed the presence of alkaloids, glycosides, saponins, tanins, flavonoids, proteins, and carbohydrates 
TABLE 1: Plant parts used and their extraction yields.

\begin{tabular}{|c|c|c|c|c|c|}
\hline No. & $\begin{array}{l}\text { Scientific name } \\
\text { (Family) }\end{array}$ & Local name (Locality) & Part used & Solvent & Extraction yield (\% w/w) \\
\hline 1 & $\begin{array}{l}\text { Cuviera longiflora } \\
\text { (Rubiaceae) }\end{array}$ & ND & Leaves & $\mathrm{CH}_{2} \mathrm{Cl}_{2} / \mathrm{MeOH}(1: 1)$ & 1.40 \\
\hline 2 & $\begin{array}{l}\text { Dacryodes edulis } \\
\text { (Burseraceae) }\end{array}$ & Zo’o (Batcham) & Leaves & $\mathrm{CH}_{2} \mathrm{Cl}_{2} / \mathrm{MeOH}(1: 1)$ & 1.68 \\
\hline 3 & $\begin{array}{l}\text { Eucalyptus globules } \\
\text { (Myrtaceae) }\end{array}$ & Klatusse (Batcham) & Leaves & $\mathrm{CH}_{2} \mathrm{Cl}_{2} / \mathrm{MeOH}(1: 1)$ & 2.02 \\
\hline \multirow{3}{*}{4} & \multirow{3}{*}{$\begin{array}{l}\text { Kotschya speciosa } \\
\text { (Leguminoceae) }\end{array}$} & \multirow{3}{*}{ ND } & Whole plan & $\mathrm{CH}_{2} \mathrm{Cl}_{2}$ & 0.86 \\
\hline & & & Aerial part & Hexane & 0.52 \\
\hline & & & Aerial part & $\mathrm{CH}_{2} \mathrm{Cl}_{2}$ & 0.64 \\
\hline 5 & $\begin{array}{l}\text { Coula edulis } \\
\text { (Olacaceae) }\end{array}$ & Walnut (Batcham) & Stem bark & $\mathrm{MeOH}$ & 0.78 \\
\hline \multirow{2}{*}{6} & \multirow{2}{*}{$\begin{array}{l}\text { Vernonia amygdalina } \\
\text { (Asteraceae) }\end{array}$} & \multirow{2}{*}{ Bitter leaf (Batcham) } & Leaves & $\mathrm{CH}_{2} \mathrm{Cl}_{2}$ & 1.75 \\
\hline & & & Root bark & $\mathrm{CH}_{2} \mathrm{Cl}_{2}$ & 1.85 \\
\hline 7 & $\begin{array}{l}\text { Vismia guinensis } \\
\text { (Asteraceae) }\end{array}$ & $\mathrm{ND}$ & Stem bark & $\begin{array}{c}\mathrm{CH}_{2} \mathrm{Cl}_{2} \\
\mathrm{CH}_{2} \mathrm{Cl}_{2} / \mathrm{MeOH}(1: 1)\end{array}$ & $\begin{array}{l}1.12 \\
1.84 \\
\end{array}$ \\
\hline
\end{tabular}

$\mathrm{CH}_{2} \mathrm{Cl}_{2} / \mathrm{MeOH}(1: 1)$ : methylene chloride/methanol mixture (1:1); $\mathrm{CH}_{2} \mathrm{Cl}_{2}$ : methylene chloride; $\mathrm{MeOH}$ : methanol; \%w/w: percentage weight/Weight; ND: not determined.

TABLE 2: Antiplasmodial activity and cytotoxicity of the tested products.

\begin{tabular}{|c|c|c|c|c|c|}
\hline $\begin{array}{l}\text { Scientific name } \\
\text { (Family) }\end{array}$ & Part used (Code) & $\mathrm{IC}_{50}$ on $3 \mathrm{D} 7(\mu \mathrm{g} / \mathrm{mL})$ & $\mathrm{IC}_{50}$ on DD2 $(\mu \mathrm{g} / \mathrm{mL})$ & $\begin{array}{c}\mathrm{CC}_{50} \text { on LLC/MK2 } \\
(\mu \mathrm{g} / \mathrm{mL})\end{array}$ & $\begin{array}{c}\text { SI on 3D7 (SI on } \\
\text { DD2) }\end{array}$ \\
\hline Cuviera longiflora & Leaves (CLL) & $20.24 \pm 4.95$ & $13.91 \pm 0.65$ & 250 & $12.35(17.91)$ \\
\hline $\begin{array}{l}\text { Dacryodes edulis } \\
\text { (Burseraceae) }\end{array}$ & Leaves (DEL) & $6.45 \pm 0.88$ & $8.62 \pm 1.44$ & $>1000$ & ND \\
\hline Eucalyptus globulus & Leaves (EGL) & $16.80 \pm 8.35$ & $26.45 \pm 3.32$ & 208.33 & $12.40(7.88)$ \\
\hline \multirow{3}{*}{ Kotschya speciosa } & Whole plant (KS) & $48.29 \pm 4.46$ & $108.89 \pm 17.21$ & $>1000$ & $\mathrm{ND}$ \\
\hline & Aerial part (KSH) & $22.61 \pm 10.34$ & ND & 625 & 27.64 \\
\hline & Aerial part (KSR) & $64.30 \pm 12.76$ & $59.30 \pm 8.32$ & $>1000$ & ND \\
\hline Coula edulis & Stem bark (CE) & $13.80 \pm 3.25$ & $5.79 \pm 1.33$ & 178.57 & $12.94(30.84)$ \\
\hline \multirow{2}{*}{ Vernonia amygdalina } & Leaves (VAL) & $8.72 \pm 2.11$ & $11.27 \pm 2.06$ & $>1000$ & $\mathrm{ND}$ \\
\hline & Root bark (VAR) & $9.01 \pm 1.11$ & ND & $>1000$ & ND \\
\hline \multirow{2}{*}{ Vismia guinensis } & Stem bark (VGE) & $43.42 \pm 2.76$ & $4.735 \pm 3.54$ & $>1000$ & $\mathrm{ND}$ \\
\hline & Stem bark (VGS) & $65.29 \pm 7.58$ & $62.5 \pm 12.45$ & $>1000$ & ND \\
\hline Chloroquine & & 0.10 & $0.95 \pm 0.01$ & - & - \\
\hline
\end{tabular}

$\mathrm{IC}_{50}$ : inhibition 50\%, $\mathrm{CC}_{50}$ : cytotoxic concentration 50\%, each value represents the average and standard deviation obtained from 6 different measurements; ND: not determined.

[16]. Alkaloids are one of the most important classes of natural products providing drugs since ancient times. The outstanding example is quinine from Cinchona succirubra (Rubiaceae) used for the treatment of malaria for more than three centuries [17]. Equally, flavonoids are shown to inhibit the malaria parasite growth through the L-glutamine pathway although their exact mechanism of action is yet to be clarified [18]. Several plants of the Asteraceae (Compositeae) family have been revealed as good source for antimalarials, the most famous one being Artemisia annua the Chinese herb from which artemisinin (quinghaosu) was isolated [19]. Equally, Lupeol was identified as a compound responsible for the antimalarial activity of the Vernonia brasiliana leaves, inhibiting the $P$. falciparum growth by $45 \%$ when tested at $25 \mu / \mathrm{mL}$. The high activity observed from the present investigation with both leaves and roots of $V$. amygdalina which is a member of this family thus supports the use of this plant for malaria by traditional healers.

Phytochemical screening of Coula edulis by AdebayoTayo and Ajibesin [20] revealed the presence of alkaloids, glycosides, saponins, tanins, flavonoids, and terpenes [20]. C. edulis has been shown to exhibit a wide range of antimicrobial and antifungal activities but from the literature, the antiplasmodial activity of this species has not previously been reported. The presence of compounds like alkaloids, saponins, flavonoids, and glycosides may be the source of the 
antiplasmodial activity exhibited by this plant. Our findings, therefore, corroborate the use of $C$. edulis as antimalarial in Cameroonian folk medicine.

Eucalyptus globulus which is widely employed by traditional healers of Western Cameroon for malaria has previously been studied for its postulated properties [4]. Previous studies have revealed E. globulus to be a good source of antimicrobial leads [21]. The leaves of Eucalyptus robusta (another plant of the same genus) are used in China for the treatment of dysentery, malaria, and bacterial diseases. Three active compounds, Robustaol A, Robustadial A, and Robustadial B, were isolated from the ethanol extract of the leaves [22]. The present work on the crude extract from leaves agree with these previous findings, justifying the wide use of E. globulus as antimalarial by endogenous traditional healers of Western Cameroon.

Cuviera longiflora is a medicinal plant commonly used across the continent and out of Africa to treat various ailments. No report on investigation of this plant for its biological activity was found. The results obtained from our study reveal that $C$. longiflora has antimalarial properties. Further phytochemical screening may lead to identification of ingredients responsible for the observed antiplasmodial activity of the plant.

All the tested extracts were found to be noncytotoxic or with very low toxicity on LLC/MK2 monkey kidney epithelial cells. This observation may be an indicator of their safety as drugs for mammalian organisms. Some of the plants tested in this study like $V$. amygdalina and D. edulis are widely used in many African countries including Nigeria and Cameroon for both therapeutic and nutritional purposes [23]. No part of D. edulis is known to be toxic, except the presence of some antinutrient factors such as oxalate, tannins, phytates, and trypsin-inhibitors in the seeds $[24,25]$.

\section{Conclusions}

From this study, it was observed that Dacryodes edulis, Vernonia amygdalina, Coula edulis, Eucalyptus globules, and Cuviera longiflora possess significant antiplasmodial activities. Both leaves and roots of $V$. amygdalina showed high antiplasmodial activity with no cytotoxicity. The results obtained justify the use of these plants by traditional healers of Western Cameroon. Further investigations on some of these plants, especially including bioassay-guided fractionation of extracts from $D$. edulis, V. amygdalina, and Coula edulis, are likely to yield new antimalarial drug leads.

\section{Acknowledgments}

This work received financial support in the form of Research Grants awarded to Professor V. P. K. Titanji by the International Programme in the Chemical Sciences (IPICS, CAM 01), Microsoft Corporation and The University of Buea. The authors are also very grateful to MR4 (Manassas, VA, USA) and Professor Alex Rowe (Edinburgh University, UK) who generously donated the parasites strains used in this study.

\section{References}

[1] WHO, World Malaria Report: 2010, WHO Press, Geneva, Switzerland, 2010.

[2] WHO, World Malaria Report: 2008, WHO Press, Geneva, Switzerland, 2008.

[3] D. Zofou, C. Teugwa Mofor, and P. H. Amvam Zollo, "Etude socio-épidémiologique du paludisme dans la localité de Mbouda (Ouest Cameroun)," Médecine d'Afrique Noire, vol. 56, no. 1, pp. 91-95, 2008.

[4] W. Mbacham, C. Roper, G. Targett, and B. Grenwood, "Antimalarial drug resistance in Cameroon: therapeutic efficacy and biological markers of resistance," Gates Malaria Partnership Annual Report, p. 13, 2004.

[5] V. P. K. Titanji, D. Zofou, and M. N. Ngemenya, "The antimalarial potential of medicinal plants used for the treatment of malaria in Cameroonian Folk Medicine," African Journal of Traditional, Complementary and Alternative, vol. 5, no. 3, pp. 302-321, 2008.

[6] A. M. Dondorp, F. Nosten, P. Yi et al., "Artemisinin resistance in Plasmodium falciparum malaria," New England Journal of Medicine, vol. 361, no. 5, pp. 455-467, 2009.

[7] P. Tane, H. K. Wabo, and J. D. Connolly, "A new benzophenanthridine alkaloid from Zanthoxylum buesgenii," Fitoterapia, vol. 76, no. 7-8, pp. 656-660, 2005.

[8] S. Nkhoma, M. Molyneux, and S. Ward, "In vitro antimalarial susceptibility profile and Prcrt/Pfmdr-1 genotypes of Plasmodium falciparum field isolates from Malawi," American Journal of Tropical Medicine and Hygiene, vol. 76, no. 6, pp. 1107-1112, 2007.

[9] M. N. Ngemenya, T. M. Akam, J. N. Yong et al., "Antiplasmodial activities of some products from Turreanthus africanus (Meliaceae)," African Journal of Health Sciences, vol. 13, no. 12, pp. 33-39, 2006.

[10] R. E. Desjardins, C. J. Canfield, J. D. Haynes, and J. D. Chulay, "Quantitative assessment of antimalarial activity in vitro by a semiautomated microdilution technique," Antimicrobial Agents and Chemotherapy, vol. 16, no. 6, pp. 710-718, 1979.

[11] H. M. Malebo, W. Tanja, M. Cal et al., "Antiplasmodial, anti-trypanosomal, anti-leishmanial and cytotoxicity activity of selected Tanzanian medicinal plants," Tanzania Journal of Health Research, vol. 11, no. 4, pp. 226-234, 2009.

[12] P. T. Mpiana, D. S. T. Tshibangua, O. M. Shetondea, and K. N. Ngboluab, "In vitro antidrepanocytary actvity (anti-sickle cell anaemia) of some Congolese plants," Phytomed, vol. 14, pp. 192-195, 2007.

[13] A. R. Walker and R. Silans, Les plantes Utiles du Gabon, Paul Lechevalier, Paris, France, 1961.

[14] A. Bouquet, Feticheur et Medecine Traditionelle du Congo (Brazzaville). O.R.S.T.O.M., Mémoire, 1-100, 1969.

[15] S. Saxena, N. Pant, D. C. Jain, and R. S. Bhakuni, "Antimalarial agents from plant sources," Current Science, vol. 85, no. 9, pp. 1314-1329, 2003.

[16] M. A. Mamoh, M. U. Adikwu, and A. R. Oyi, "Vernonia amygdalina extract and CD4+ cell counts: an immune study," Global Journal of Biotechnology' Biochemistry, vol. 5, no. 2, pp. 92-96, 2010.

[17] K. Kaur, M. Jain, T. Kaur, and R. Jain, "Antimalarials from nature," Bioorganic and Medicinal Chemistry, vol. 17, no. 9, pp. 3229-3256, 2009.

[18] B. C. Elford, "L-Glutamine influx in malaria-infected erythrocytes: a target for antimalarials?" Parasitology Today, vol. 2, no. 11, pp. 309-312, 1986. 
[19] K. C. S. C. Liu, S. L. Yang, M. F. Roberts, B. C. Elford, and J. D. Phillipson, "Antimalarial activity of Artemisia annua flavonoids from whole plants and cell cultures," Plant Cell Reports, vol. 11, no. 12, pp. 637-640, 1992.

[20] B. C. Adebayo-Tayo and K. K. Ajibesin, "Antimicrobila activity of coula edulis," Research Journal of Medicinal Plant, vol. 2, no. 2, pp. 86-91, 2008.

[21] R. G. Bachir and M. Benali, "Antibacterial activity of leaf essential oils of Eucalyptus globulus and Eucalyptus camaldulensis," African Journal of Pharmacy and Pharmacology, vol. 2, no. 10, pp. 211-215, 2008.

[22] R. S. Xu, J. K. Snyder, and K. Nakanishi, "Robustadials A and B from Eucalyptus robusta," Journal of the American Chemical Society, vol. 106, no. 3, pp. 734-736, 1984.

[23] E. M. Arhoghro, K. E. Ekpo, E. O. Anosike, and G. O. Ibeh, "Effect of aqueous extract of bitter leaf (Vernonia Amygdalina $\mathrm{Del})$ on carbon tetrachloride $(\mathrm{CCl})$ induced liver damage in albino wistar rats," European Journal of Scientific Research, vol. 26, no. 1, pp. 122-130, 2009.

[24] I. Hanson, "Toxicants and physicochemical characteristics of the seeds of African Pear (Dacryodes edulis)," African Journal of Food, Agriculture, Nutrition and Development, vol. 9, pp. 15611562, 2009.

[25] K. K. Ajibesin, "Dacryodes edulis (G. Don) H.J. Lam: a review on its medicinal, phytochemical and economical properties," Research Journal of Medicinal Plant, vol. 5, no. 1, pp. 32-41, 2011. 


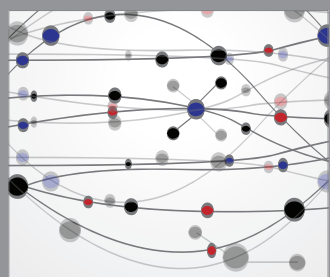

The Scientific World Journal
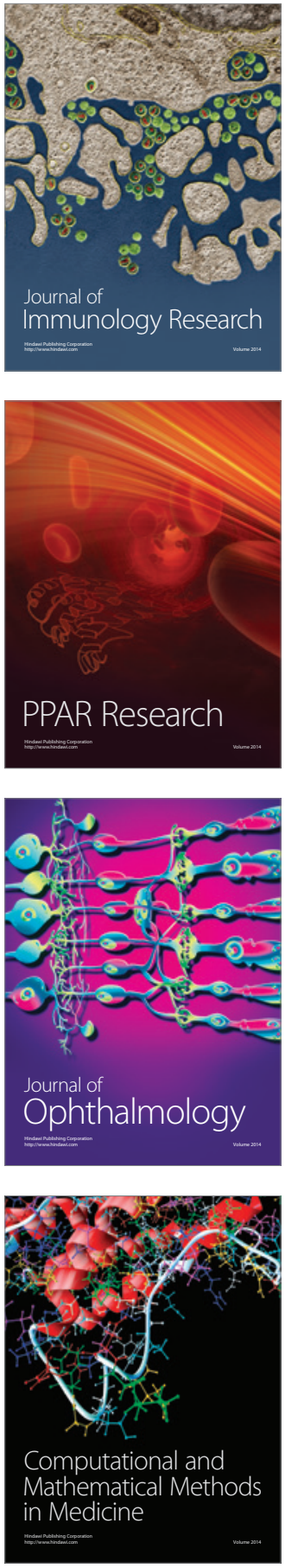

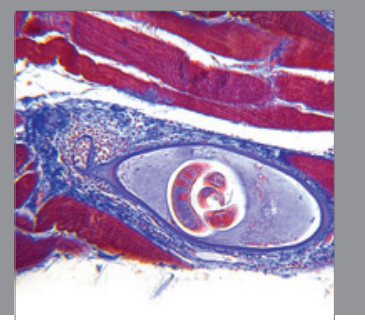

Gastroenterology

Research and Practice
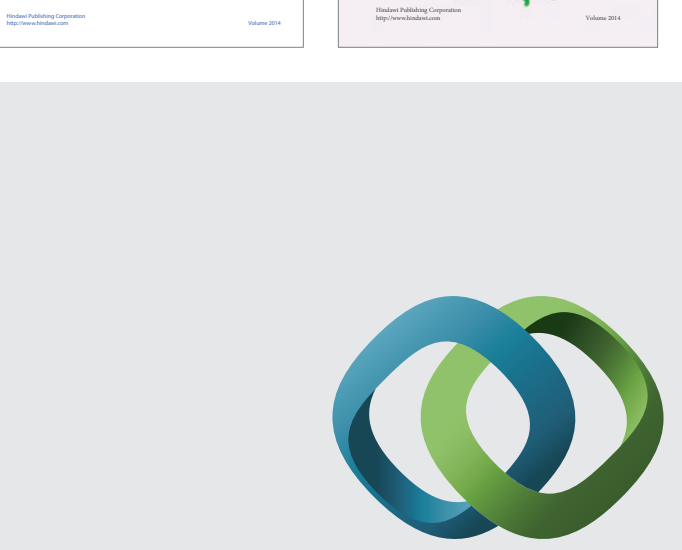

\section{Hindawi}

Submit your manuscripts at

http://www.hindawi.com
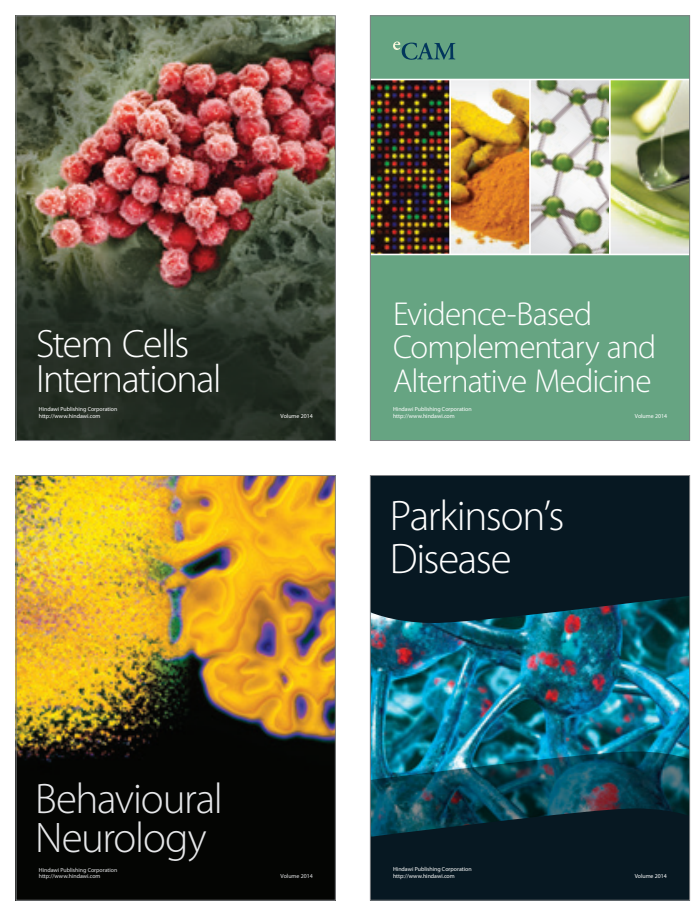

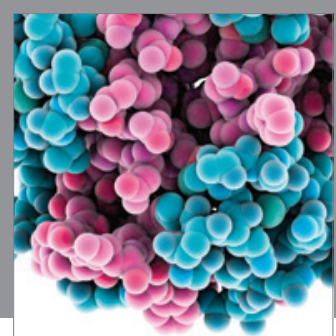

Journal of
Diabetes Research

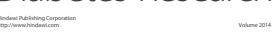

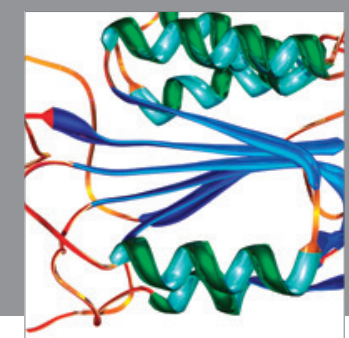

Disease Markers
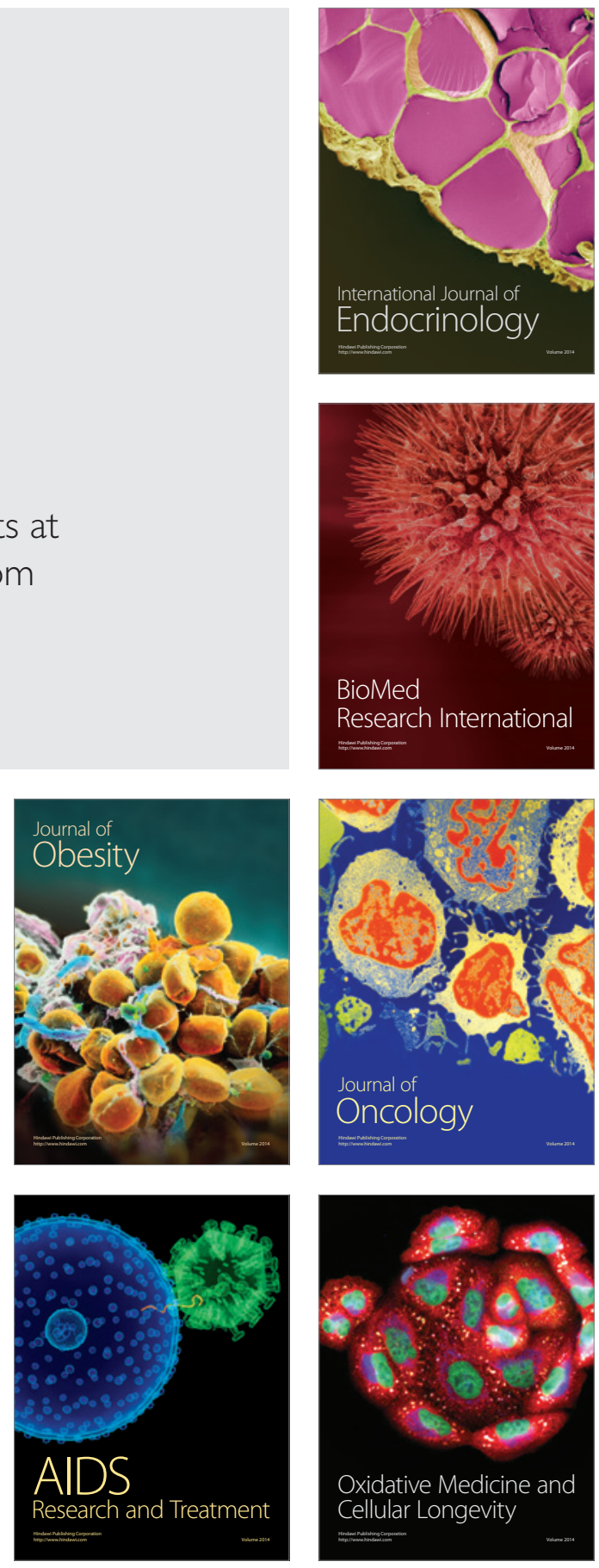